\title{
Ocular changes in limited forms of Wegener's granulomatosis
}

\author{
D. J. SPALTON, E. M. GRAHAM, N. G. R. PAGE, ANd M. D. SANDERS \\ From the Medical Eye Unit, St Thomas's Hospital, London SEl
}

SUMMARY Eight patients who had limited forms of Wegener's granulomatosis are described, with details of their pathology. Ocular pathological data were available for 2 of them. The condition carries a serious ocular risk; useful vision was lost in 6 out of 16 eyes (37\%). An indolent but slowly progressive marginal keratitis and scleritis was a prominent feature in 4 patients and was helpful in suggesting the diagnosis. Limited forms of Wegener's granulomatosis carry a better prognosis and response to treatment than the classical disease.

Wegener's granulomatosis is characterised by necrotising granulomas of the respiratory tracts, renal failure, and a disseminated focal necrotising angiitis of small arteries and veins. ${ }^{1-3}$ In classical Wegener's granulomatosis respiratory tract involvement precedes that of other systems, but the disease is rapidly progressive, and death usually results from a focal necrotising glomerulonephritis. Before the advent of steroid and cytotoxic therapy Wegener's granulomatosis carried a disastrous prognosis; the average survival was 5 months and $80 \%$ of patients were dead within a year of diagnosis. ${ }^{4}$ More recently forms or types of Wegener's granulomatosis that are limited to one system or part of the body have been recognised, and these usually carry a much better prognosis. ${ }^{56}$ The response to therapy is better, and after initial treatment some patients go into remission or only require a small dose of maintenance therapy. ${ }^{7}$

Ocular involvement in Wegener's granuloma is common, affecting about $40 \%$ of patients with generalised disease, ${ }^{489}$ and patients frequently present initially to the ophthalmologist. This high rate of ocular involvement is partly due to the proximity of the orbit to the upper airways, but isolated ocular involvement occurs as part of a focal necrotising vasculitis. Because of the diversity of the ocular manifestations and the rarity of the disease, Wegener's granulomatosis presents a difficult clinical diagnostic problem, and we report here our experience with 8 patients.

Correspondence to Mr D. J. Spalton, FRCS, Charing Cross Hospital, Fulham Palace Road, London W6.

\section{Patients and methods}

This small series of 8 patients includes 4 men and 4 women with an age range from 12 to 65 years. Three patients had predominantly anterior segment involvement, 3 had orbital or intracranial disease, 1 had retinal disease, and 1 had a central retinal vein thrombosis and anterior segmental involvement.

All patients had involvement of either the upper or lower respiratory tract, but only 1 patient had evidence of renal damage. Neurological involvement was reflected as a brainstem stroke in patient 4 , a transverse myelitis in patient 8 , and intracranial invasion from the orbit in patients 5 and probably patient 7 . These findings are summarised in Table 1.

Pathological material from patients 1, 3, 5, and 6 showed necrotising granulomatosis and vasculitis, the condition in patient 8 was compatible with the necrotising sarcoidal and granulomatosis form of Wegener's granulomatosis described by Liebow, ${ }^{6}$ and patient 7 had a necrotising vasculitis without granuloma formation on nasal biopsy. Patient 4's condition was diagnosed by renal and ocular pathology and probable sinus disease, though nasal biopsy was negative. Patient 2 had an extensive granulomatous involvement of the eyelids with some allergic features, though no vascular necrosis could be demonstrated in the sections available. Ocular pathology was available on patients 3 and 4. 
Table 1 Ocular and systemic involvement in 8 patients with Wegener's granulomatosis

\begin{tabular}{|c|c|c|c|c|c|c|c|c|c|c|c|c|}
\hline \multirow{2}{*}{ Patient } & \multicolumn{8}{|c|}{ Ocular involvement } & \multicolumn{4}{|c|}{ Systemic involvement } \\
\hline & Lids & Conjunctiva & Sclera & Cornea & Uveitis & $\begin{array}{l}\text { Retinal } \\
\text { vasculitis }\end{array}$ & $\begin{array}{l}C R A O \\
C R V O\end{array}$ & Orbit & $\begin{array}{l}\text { Upper } \\
\text { airways }\end{array}$ & Lungs & Kidnevs & CNS \\
\hline 1 & - & + & + & + & \pm & - & - & - & + & + & - & - \\
\hline 2 & + & + & + & + & \pm & - & - & - & + & - & - & - \\
\hline 3 & - & + & + & + & + & - & - & - & + & + & - & - \\
\hline 4 & - & - & - & + & + & - & CRVT & - & + & - & + & $\begin{array}{l}\text { Focal } \\
\text { vasculitis }\end{array}$ \\
\hline 5 & - & - & - & - & - & - & - & + & + & - & - & $\begin{array}{l}\text { Local } \\
\text { invasion }\end{array}$ \\
\hline 6 & - & - & - & - & - & - & - & + & + & + & - & - \\
\hline 7 & - & - & - & - & - & - & - & \pm & + & - & - & $\begin{array}{l}\text { Local } \\
\text { invasion }\end{array}$ \\
\hline 8 & - & - & - & - & - & + & - & - & - & + & - & $\begin{array}{l}\text { Focal } \\
\text { vasculitis }\end{array}$ \\
\hline
\end{tabular}

$\mathrm{CRAO}=$ central retinal artery occlusion. $\mathrm{CRVO}=$ central retinal vein occlusion. $\mathrm{CRVT}=$ central retinal vein thrombosis.

\section{Results}

\section{CASE 1}

Conjunctival and corneal changes. A 64-year-old man presented with a 4-month history of weight loss of 20 lb $(9 \mathrm{~kg})$, recent onset of soreness and grittiness in his eyes, a hoarse voice, and bleeding from the right nostril. There was no previous relevant history. On examination the acuity was $6 / 5$ in each eye and the abnormal findings were a bilateral nodular scleritis with marginal infiltration of the corneae (Fig. 1). Ocular examination was otherwise normal. His ocular symptoms were treated with topical steroids and phenylbutazone, with some slight improvement over several weeks. A chest $x$-ray showed a cavitating lesion in the apex of the left lung, and he was referred for further investigation.

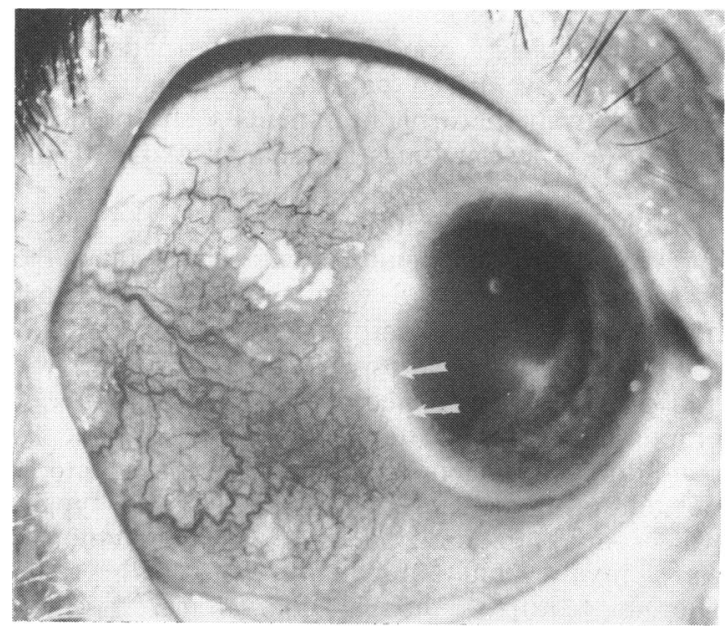

Fig. 1 Case 1. The right eye showing patchy scleritis with adjacent limbal marginal infiltrates (arrows).
Relevant investigations showed $\mathrm{Hb} 11.6 \mathrm{~g} / \mathrm{dl}$, leucocytes normal, ESR $80 \mathrm{~mm} / \mathrm{h}, \mathrm{PCV} 0 \cdot 38$, MCV $86 \mathrm{fl}, \mathrm{MCHC} 30.9 \mathrm{~g} / \mathrm{dl}$, urea $4 \mathrm{mmol} / \mathrm{l}$, creatinine clearance $87 \mathrm{ml} / \mathrm{min}$, no proteinuria. Proteins $76 \mathrm{~g} / \mathrm{l}$, albumin $38 \mathrm{~g} / \mathrm{l}, \operatorname{IgG} 16.0 \mathrm{~g} / \mathrm{l}, \operatorname{IgA} 3.85 \mathrm{~g} / \mathrm{l}, \operatorname{IgM}$ $0.94 \mathrm{~g} / \mathrm{l}$. ANA, DNA antibodies, and rheumatoid factor were negative. Tuberculosis sputum culture and cytology were negative.

The patient had a bronchoscopy and needle biopsy of the lung lesion without definitive results, and a trial of antituberculous therapy produced no change in the lesion. A thoracotomy and lobectomy were performed. The histology showed granulation and scar tissue infiltrated by chronic inflammatory cells, with a severe arteritis and tissue necrosis with some surrounding giant cells, but no granuloma formation.

The patient was diagnosed as having pulmonary and upper respiratory tract Wegener's granulomatosis. He was started on azathioprine $150 \mathrm{mg} /$ day, with a dramatic improvement in his general health and ocular state.

Summary. A 64-year-old man developed weight loss, malaise, and an indolent marginal keratitis and scleritis over several months. He was found to have a cavitating lung lesion which was removed and shown to be due to Wegener's granulomatosis. He has maintained an excellent response to azathioprine for the last 2 years without evidence of renal involvement.

CASE 2

Eyelid necrosis and marginal keratitis. A woman aged 40 presented with a 12-week history of redness and soreness of her right eye which was diagnosed as a marginal keratitis, but failed to respond to topical treatment. Three months later the right eyelids started to swell and become indurated.

On examination the patient was obese but otherwise well, and abnormal findings were limited to her eyes. Visual acuities were 6/36 and 6/6. A discharg- 


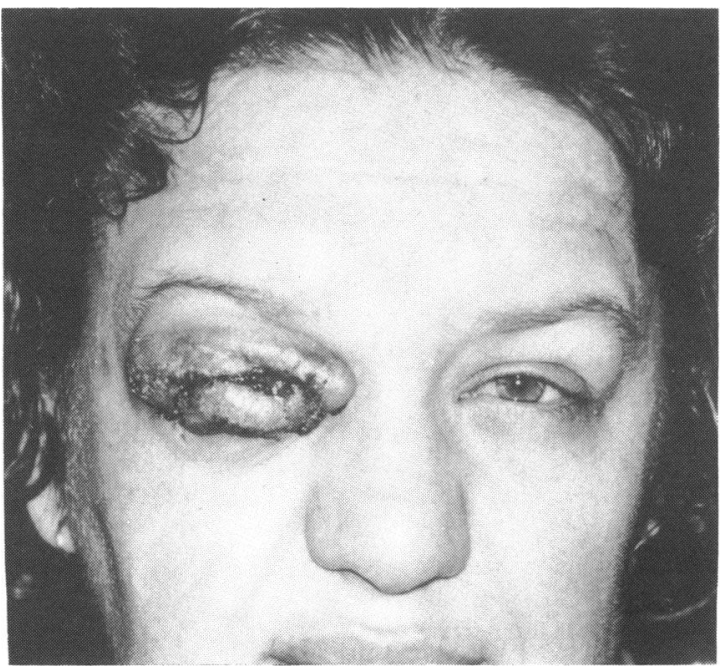

Fig. 2 Case 2. The right upper evelid is grossly swollen. indurated, and discharging and ocludes the eve.

Subcutaneous nodular lesions of the upper and lower tarsal plates could be palpated on the left.

ing, fungating, and indurated mass extended from the right upper lid into the lower lid closing the eye; similarly there was some nodular subcutaneous induration of the left eyelid (Fig. 2). The tarsal conjunctiva in the right eye showed injection, induration, and some petechial haemorrhages, and there were similar changes in the bulbar conjunctiva and episcleral tissue. The right cornea was surrounded by perilimbal ulceration and vascularisation with a few active marginal infiltrates (Fig. 3). There were similar but less marked patchy changes in the conjunctiva of the left eye, and a few active marginal corneal infiltrations could be seen (Fig. 4). The anterior

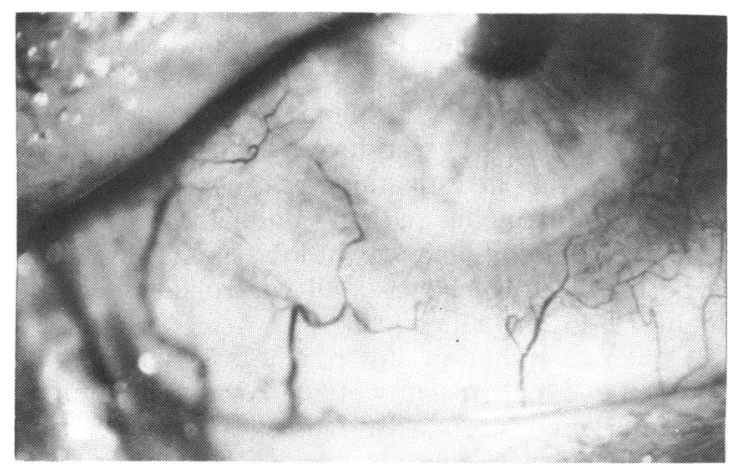

Fig. 3 Case 2. The right eye in the healing phase following systemic cytotoxic therapy showed paralimbal guttering, scarring, and vascularisation. chambers and fundi were normal. There was no proptosis, but the right preauricular gland was enlarged.

Investigations showed $\mathrm{Hb} 15.6 \mathrm{~g} / \mathrm{dl}$, leucocytes normal, ESR $64 \mathrm{~mm} / \mathrm{h}$. Serum proteins $81 \mathrm{~g} / \mathrm{l}$ (albumin $42 \mathrm{~g} / \mathrm{l}$ ), IgG $2 \cdot 09 \mathrm{~g} / \mathrm{l}, \operatorname{IgA} 2 \cdot 31 \mathrm{~g} / \mathrm{l}, \operatorname{IgM} 4 \cdot 12$ $\mathrm{g} / \mathrm{l}$. Urea $6 \cdot 2 \mathrm{mmol} / \mathrm{l}$, no proteinuria, LFTs normal. Screening for hepatitis B antigen and autoantibodies was negative. The fungating lid lesion grew Staphylococcus albus. Tests for tuberculosis, chlamydia, brucella, syphilis, cat scratch fever, and a Kveim test were negative. A chest $x$-ray was normal, but facial $x$-rays showed some sinuses were opaque. Wegener's granuloma was suspected on clinical grounds.

A nasal biopsy was performed, and this showed that the mucosa was heavily infiltrated by lymphocytes, plasma cells, and macrophages, with occasional

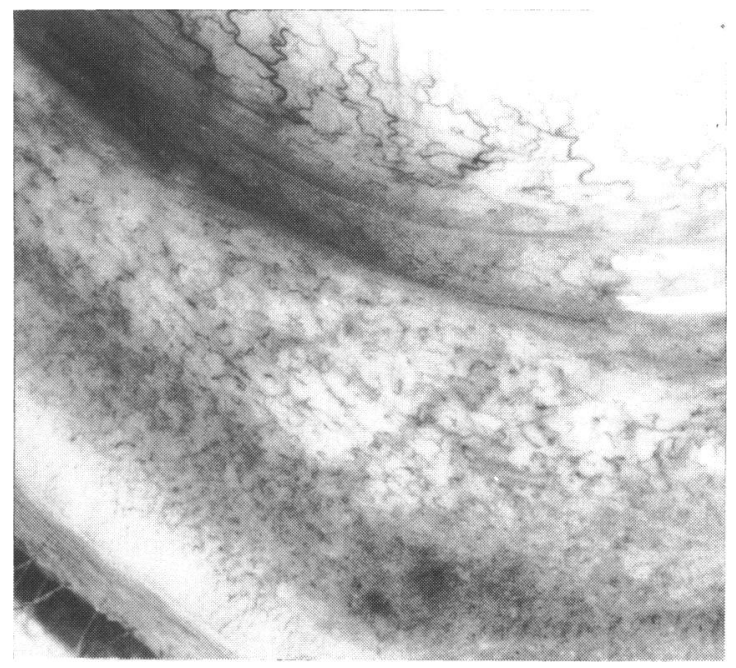

Fig. 4 Case 2. Tarsal conjunctiva of the left eye showed hyperaemia, petechial haemorrhages, induration, and oedema.

polymorphs and eosinophils forming a nonspecific picture of chronic inflammation. Biopsy of the lid lesion showed a granulomatous inflammation accompanied with neutrophils and eosinophils and some giant cells, without evidence of vascular or tissue necrosis.

Summary. A 40-year-old woman was thought to have a localised form of Wegener's granulomatosis, although tissue necrosis could not be demonstrated pathologically. She was started on treatment with steroids and cyclophosphamide. The lid lesions responded rapidly, but she required prolonged and 
careful management of her right eye as a result of damage from local inflammation and exposure from lid destruction. The cornea eventually perforated and required a keratoplasty. She had no evidence of pulmonary or renal involvement during 2 years of follow-up.

\section{CASE 3}

Necrotising scleritis and uveitis. A 37-year-old housewife presented with a 6-year history of arthritis in her hands. One and a half years after this she developed scleritis and uveitis in both eyes and was then treated with systemic steroids. Four years later she started to become anorexic, lost weight, and ruticed the hearing in her right ear was poor. She was found to have a cavitating lesion in the mid zone of the right lung and was started on antituberculous treatment, with no benefit. At about the same time the left eye became blind and painful as a result of necrotising scleritis and was enucleated 6 months later. At this time she was referred to the Medical Eye Unit.

On examination the acuity in the right eye was $6 / 5$ and ocular examination was normal apart from a mild nodular episcleritis. The left socket had failed to heal after the enucleation and was discharging from the wound. Systemic examination was normal but otolaryngological examination revealed a crusting inflammation of the nasal mucosa and a secretory otitis media of the right ear.

Investigations showed $\mathrm{Hb} 12.3 \mathrm{~g} / \mathrm{dl}$, leucocytes normal, ESR $72 \mathrm{~mm} / \mathrm{h}$, proteins $73 \mathrm{~g} / \mathrm{l}$, albumin 36 $\mathrm{g} / \mathrm{l}$; electrophoresis showed elevated alpha 1 and alpha 2 bands. IgG 15.6 g/l, IgA 3.85 g/l, IgM $1.05 \mathrm{~g} / \mathrm{l}$, $\mathrm{C} 3$ and C4 were normal. Rheumatoid factor, DNA antibodies, and syphilis serology were negative. Antinuclear factor was positive at 1:10, other autoantibodies were negative. Renal function was normal and there was no proteinuria. Chest $x$-ray confirmed the cavitating lesion in the right mid zone and sinus $x$-rays demonstrated mucosal thickening.

A nasal biopsy was performed, and the histology of this showed a necrotising giant cell granuloma with foci of acute inflammation and a chronic perivascular infiltrate. Eosinophils were present, and there was fibrinoid necrosis in some vessels. No tubercle bacilli were seen. The pathology was characteristic of Wegener's granulomatosis. She was treated with prednisolone and azathioprine and made a substantial improvement.

The pathology of the previously enucleated eye was reviewed and showed a chronic necrotising granulomatous reaction in the anterior sclera, uvea, and peripheral retina, a marked anterior uveitis, and some vascularisation of the limbus (Fig. 5).

Summary. A 37-year-old woman with a 6-year history of arthritis, uveitis, and scleritis developed

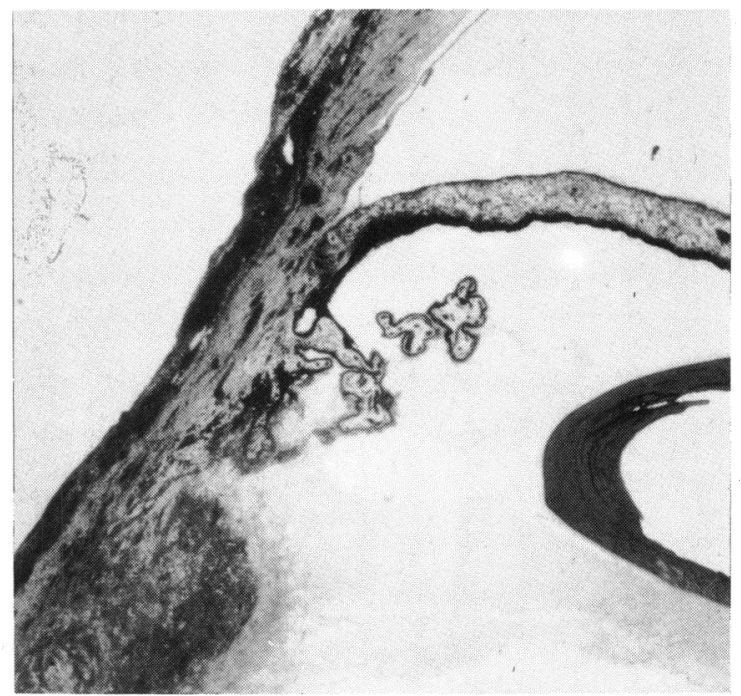

Fig. 5 Case 3. The enucleated left eye showed an intense necrotising granulomatous reaction in the anterior sclera and uveal tract with ulceration of the limbus.

malaise, lung cavitation, hearing problems, and lost one eye from necrotising scleritis. A diagnosis of Wegener's granuloma was made from nasal mucosal biopsy and review of the ocular pathology. She has been fairly well for 2 years on systemic steroids and azathioprine but has had fluctuating exacerbations, so far without signs of renal involvement.

\section{CASE 4}

Central retinal vein thrombosis, marginal keratitis, and anterior uveitis. A 65-year-old man presented with a central retinal vein occlusion in the right eye in July 1977 and this progressed to a thrombotic glaucoma. One year later he developed an anterior uveitis in the other eye, with a marginal keratitis which did not settle on topical therapy. At this time he started to feel unwell, and was found to have an ESR of $97 \mathrm{~mm} / \mathrm{Hr}$. The right eye was enucleated in November 1978 for thrombotic glaucoma and in January 1979 he was transferred to the Medical Eye Unit for further investigation.

On admission the patient complained of recent malaise, anorexia, and weight loss. He had systemic hypertension, which was well controlled on treatment. He looked thin and ill.

Ocular examination showed a normal right socket. The left eye had an acuity of $6 / 5$. Around the limbus were marginal ulcers with signs of previous scarring and a low-grade anterior uveitis. The fundus was normal.

Relevant investigations showed $\mathrm{Hb} 8 \cdot 3 \mathrm{~g} / \mathrm{dl}$, PCV $0 \cdot 25, \mathrm{MCV} 89 \mathrm{fl}, \mathrm{MCH} 27 \mathrm{pg}, \mathrm{MCHC} 32 \cdot 7 \mathrm{~g} / \mathrm{dl}$, leuco- 
cytes and platelets normal, ESR $140 \mathrm{~mm} / \mathrm{hr}$. Fibrinogen $8.46 \mathrm{~g} / \mathrm{l}(<4)$, urea $17 \mathrm{mmol} / \mathrm{l}$, creatinine clearance $24 \mathrm{ml} / \mathrm{min}$, urinary protein $2.9 \mathrm{~g} / 24 \mathrm{hr}$ (albumin+polyclonal gamma globulins). Bence Jones protein negative. Total serum protein $76 \mathrm{~g} / \mathrm{l}$, albumin $34 \mathrm{~g} / \mathrm{l}$ (alpha 1 and alpha 2 increased). IgG $15 \cdot 5 \mathrm{~g} / \mathrm{l}, \mathrm{IgA} 4 \cdot 35 \mathrm{~g} / \mathrm{l}, \mathrm{IgM} 0 \cdot 71 \mathrm{~g} / \mathrm{l}$. ANA and autoantibodies negative, hepatitis $B$ antigen negative. C3 normal, $\mathrm{C} 4$ decreased. Chest and skull $x$-rays normal. Intravenous pyelogram normal. Sinus $x$-rays showed opaque frontal and ethmoidal sinuses.

The patient had an otolaryngological examination under general anaesthesia, but biopsy of the nasal mucosa showed only inflammatory polyps. Temporal artery biopsy was normal. A renal biopsy showed proliferative glomerulonephritis with fibrinoid necrosis and some glomerulosclerosis with some tubules containing red cell and protein casts. There were a moderate focal interstitial inflammatory reaction and fibrosis, and immunofluorescence showed focal granular deposits of IgG and C3 with IgM and fibrin present to a lesser extent.

$\mathrm{Re}$-examination of the previously enucleated eye showed, apart from the signs of thrombotic glaucoma, a marked perivascular leucocytic infiltration in the bulbar conjunctiva, episclera, and anterior sclera (Fig. 6). Vessels in the anterior sclera were surrounded by chronic inflammatory cells, though there was no sign of vascular necrosis. There were patchy areas of chronic choroiditis, but the retinal vessels were free from inflammation.

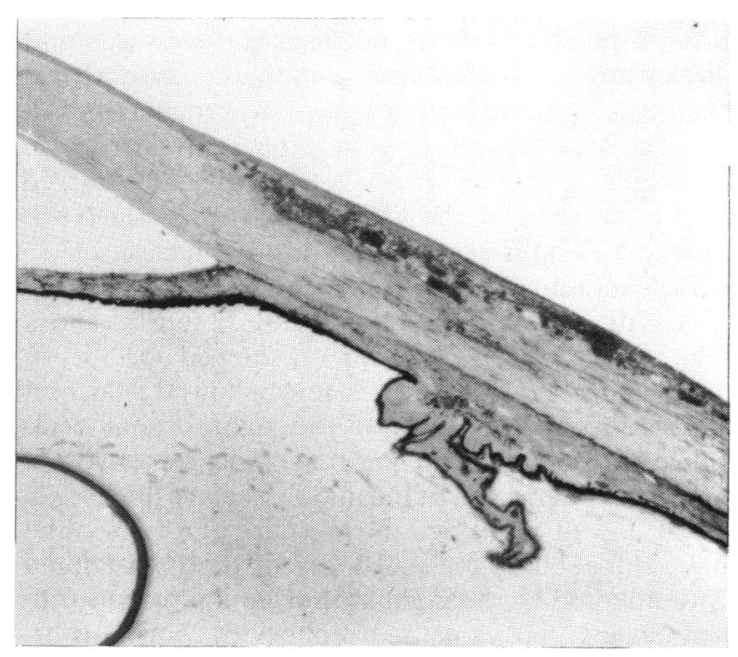

Fig. 6 Case 4. The enucleated right eye showing inflammatory infiltration of the bulbar conjunctiva, episclera, and anterior sclera in the limbal area with occlusion of the angle from thrombotic glaucoma. There was no vascular necrosis.
While in hospital the patient suffered a mild brainstem stroke from which he recovered. It was thought that the ocular and renal changes supported the clinical diagnosis of Wegener's granulomatosis, and he was started on high doses of steroids, with a rapid improvement in his condition and a fall of his ESR.

Summary. A 65-year-old man had one eye enucleated for thrombotic glaucoma. Eighteen months later he developed malaise, a high ESR, and marginal keratitis and uveitis in his remaining eye. Renal biopsy and review of the ocular pathology supported a clinical diagnosis of Wegener's granuloma, and he improved rapidly on systemic steroids.

\section{CASE 5}

Orbital and intracranial changes. A 49-year-old man presented in September 1974 with headaches and upper respiratory tract infection complicated by bilateral middle ear infection requiring myringotomies. Five months later he developed painful loss of vision in his left eye, and on examination he had reduced visual acuity and colour vision, and optic disc oedema. A diagnosis of left optic neuritis was made, and vision recovered with daily corticotrophin injections. The dosage was gradually reduced, but immediately it was stopped he suffered severe headaches and double vision. He was found to have a left sixth nerve palsy and $4 \mathrm{~mm}$ of proptosis of the left eye. A provisional diagnosis of an orbital apex syndrome was made. Investigations showed he had a normal haemoglobin and white cell count with an ESR of 32 $\mathrm{mm} / \mathrm{hr}$. Cerebrospinal fluid showed a raised protein of $70 \mathrm{mg} / 100 \mathrm{ml}(0 \cdot 7 \mathrm{~g} / \mathrm{l})$ but normal pressure and other parameters, and a carotid angiogram was normal. No definite diagnosis was made, and he was treated with dexamethasone with rapid relief of symptoms and signs. He was followed up for 2 years while repeated efforts to reduce the steroids produced exacerbation of symptoms. In January 1977 a CT scan was reported as normal.

At the end of 1977 he was referred for further investigations because of the persistently high dose of steroids that was required to control his symptoms. His main complaint was of ugly dilated conjunctival vessels in both eyes.

On examination visual acuity was $6 / 5$ in the right eye and $6 / 6$ in the left with full visual fields. There was marked dilatation of the conjunctival vessels on both eyes (Fig. 7) and increased orbital tensions, but no proptosis. The intraocular pressures were normal. External ocular movements were full. The optic discs were swollen, with choroidal folds in each eye. A CT scan showed a mass in both orbits (Fig. 8). Haematological, biochemical, and simple immunological investigations were all normal. A TRH stimulaticin test was flat. Cerebrospinal fluid had a high 


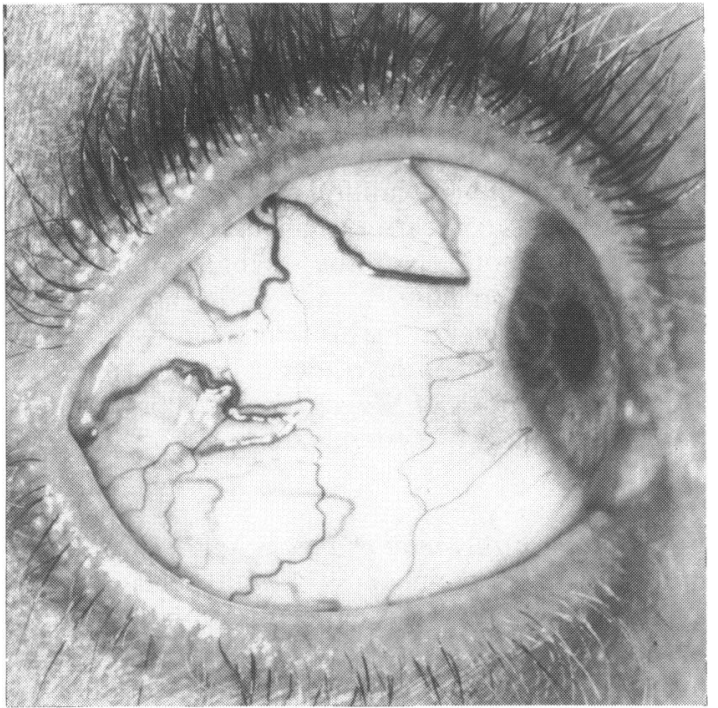

Fig. 7 Case 5. The right eye showing the dilated conjunctival and episcleral vessels on the lateral aspect of the globe, resulting from raised orbital tension.

opening pressure of $320 \mathrm{~mm}$ CSF with normal constituents.

Reduction of steroids produced a rapid drop in visual acuity of the left eye to counting fingers and development of proptosis with increased disc oedema and choroidal folds. He was treated by orbitocranial decompression, and biopsy of the thickened meninges showed clusters of leucocytes around blood vessels with lymphocytes, histiocytes, plasma cells, and eosinophils and zones of necrotic tissue consistent with Wegener's granulomatosis. Postoperatively vision returned to $6 / 6$. Immunosuppressive drugs were introduced, and for the past 2 years he has been maintained on dexamethasone and azathioprine without evidence of pulmonary or renal involvement.

Summary. A 49-year-old man with a past history of middle ear disease developed proptosis and diplopia highly sensitive to steroid therapy. A diagnosis was finally made at surgical decompression, when infiltration of meninges and orbit was found producing raised intracranial pressure and optic nerve compression. Since the introduction of immunosuppressive therapy the disease has remained localised and relatively quiescent.

CASE 6

Lacrimal, orbital, and optic nerve changes. A 42-yearold Italian woman presented in December 1968 with a 2-month history of pain and discharge from her right

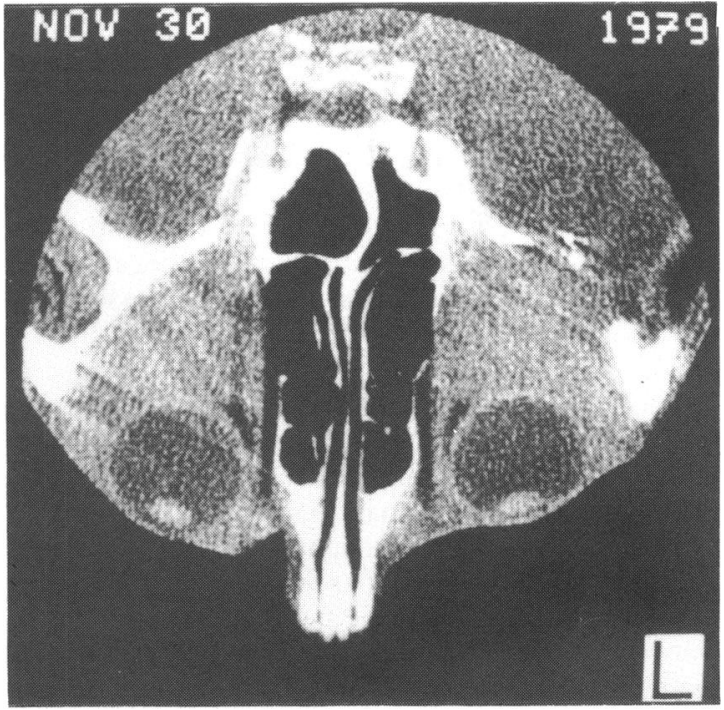

Fig. 8 Case 5. CT scan showing bilateral retrobulbar orbital infiltration and a lateral decompression of the left orbit into the middle cranial fossa.

ear, epistaxis, a right seventh nerve palsy, and a lump in her left breast.

Three months later she developed protrusion of her right eye associated with bilateral epiphora. Visual acuity was $6 / 9$ in the right eye and $6 / 5$ in the left with normal colour vision and full visual fields. Examination of the left eye was normal. The right eye was proptosed $14 \mathrm{~mm}$ and displaced forwards and downwards. There was marked conjunctival chemosis, and the orbital tension was increased. All external ocular movements were markedly decreased. The right lacrimal gland was easily palpable, enlarged and nodular, and the right nasolacrimal duct was blocked. Fundus examination was normal.

Relevant investigations revealed a haemoglobin of $11 \cdot 1 \mathrm{~g} / \mathrm{dl}$, normal leucocytes, ESR $72 \mathrm{~mm} / \mathrm{h}$, and a high IgA of $24.50 \mathrm{~g} / \mathrm{l}$. Chest $x$-ray showed opacities in both lung fields. Sinus $x$-rays showed mucosal thickening and erosion of the right orbital wall. Intravenous pyelogram and renal function tests were normal. The mucosa of the middle ear was thickened.

A CT scan confirmed the presence of a mass in the right retrobulbar space. Biopsy of the breast lump and enlarged lacrimal gland showed infiltration with histiocytes, plasma cells, lymphocytes, polymorphs, and eosinophils, with giant cell formation. The blood vessels showed perivascular fibrosis and fibrinoid necrosis and confirmed the diagnosis of Wegener's granulomatosis. Treatment with systemic prednisolone was started. There was little symptomatic 
improvement, but her ESR and immunoglobulins returned to normal levels. For the past 8 years she has been maintained on varying doses of systemic prednisolone with cyclophosphamide and azathioprine. She still has $11 \mathrm{~mm}$ proptosis of the right eye, but has now developed pallor of the right optic disc.

Summary. A 42-year-old Italian woman with upper respiratory, lung, and breast lesions developed proptosis. Wegener's granulomatosis was diagnosed by biopsy of the breast and lacrimal gland lesions. She has had symptomatic improvement on steroids and immunosuppressive drugs, but has developed optic atrophy due to long-standing optic nerve compression.

CASE 7

Bilateral optic nerve compression. A 31-year-old woman from Monserrat developed pain and loss of vision in her left eye in June 1979. Full investigation revealed an ESR of $36 \mathrm{~mm} / \mathrm{hr}$ and CSF proteins of $0.49 \mathrm{~g} / \mathrm{l}$, but $x$-rays including carotid angiography and CT scan were normal. A diagnosis of optic neuritis was made. The headaches persisted and were occasionally associated with epistaxis. In January 1980 the visual acuity in the right eye dropped over 5 weeks to counting fingers. She now had bilateral optic atrophy but no other abnormal signs. Otolaryngological examination was unremarkable. Repeat investigation showed a protein of $60 \mathrm{~g} / \mathrm{l}$ and white cells in the CSF $12 \times 10^{6} / \mathrm{l}$, ESR of $37 \mathrm{~mm} / \mathrm{h}$, but normal air encephalogram and CT scan. No diagnosis was made, and she was treated with prednisolone $60 \mathrm{mg}$ daily with some initial improvement in visual acuity. However, in April 1980 she developed a left third nerve palsy which spontaneously improved without treatment. In June her ESR rose to $60 \mathrm{~mm} / \mathrm{hr}$, and she was given a course of steroids with azathioprine which relieved her headaches, but she quickly stopped taking the tablets and declined further investigation. In November 1980 she was readmitted after she developed a right third nerve palsy.

On examination the left eye could not perceive light and she could see hand movements with the right eye. She had bilateral optic atrophy, a complete right third nerve palsy, and a residual left third nerve palsy. Her ESR had risen to $81 \mathrm{~mm} / \mathrm{hr}$.

An orbital CT scan demonstrated a parasellar mass and some opacity of ethmoid air cells extending to the frontal sinus (Figs. 9A and B). Biopsy of this mass showed areas of necrotising vasculitis and dense hyaline tissue with a marked inflammatory infiltration consistent with Wegener's granulomatosis.

Summary. A 31-year-old West Indian woman presented with rapid visual loss in each eye over 6 months and after this she developed bilateral third nerve palsies. At this time investigations revealed a

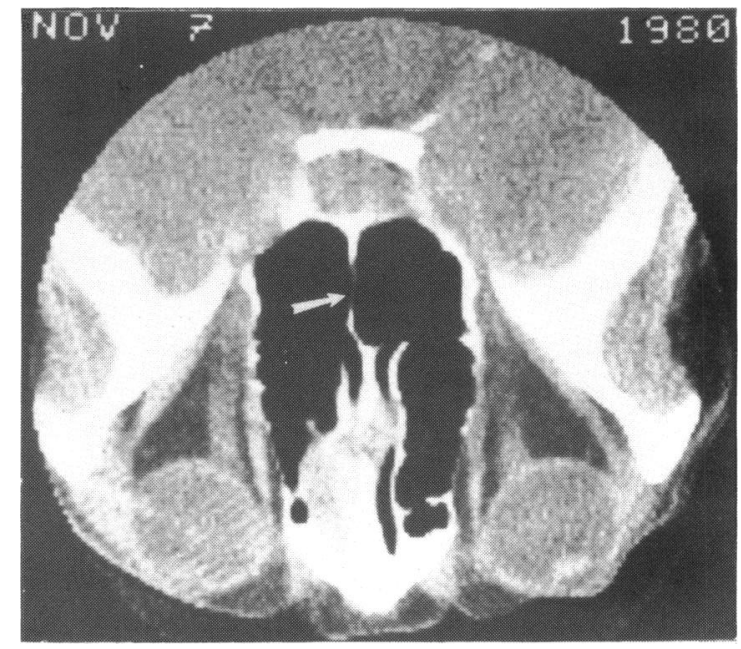

Fig. 9A Case 7. Axial CT scan showing infiltration of the nasal cavity with perforation of the septum (arrow). Both orbits are normal.

mass in her sinuses and parasellar region, and a definite diagnosis was made by biopsy of the nasal mucosa.

\section{CASE 8}

Retinal, lung, and neurological changes. A 12-yearold boy from the Canary Isles presented in March 1979 complaining of blurred vision in the right eye for 3 weeks. He had been well until 6 months previously,

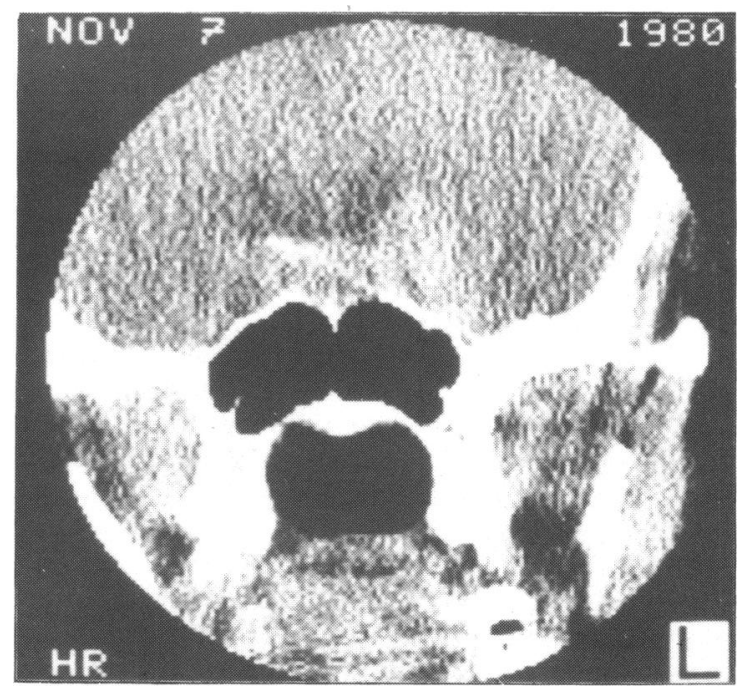

Fig. 9B Case 7. Coronal CT scan through the sphenoid sinus showing parasellar lesions, better seen on the left side. Optic nerve damage was thought to result from infiltration and compression intracranially. 


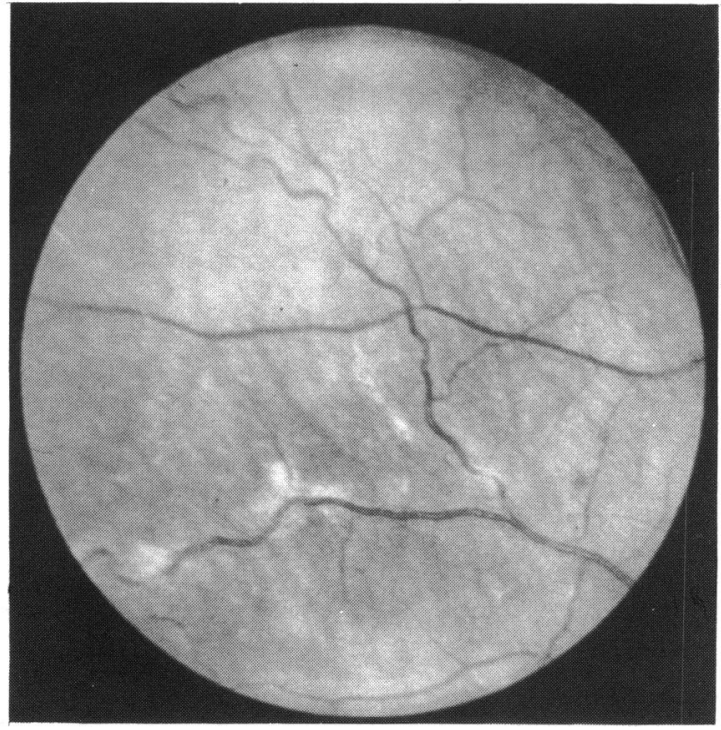

Fig. 10 Case 8. The right temporal retina showing a focal periphlebitis with areas of associated pigment epithelial atrophy.

when he developed progressive paraesthesiae and weakness in his legs associated with urinary retention. A diagnosis of acute polyneuritis was made and he was treated with injections of $\mathrm{B}_{12}$, dexamethasone, and gamma globulin, with rapid improvement. Two months later he developed a right lower lobe pneumonia accompanied by some relapse of his neurological signs, which were slow to improve. He returned home and was lost to follow-up.

In March 1979 he was readmitted with a further exacerbation of the weakness of his legs and incontinence of urine and faeces, together with blurred vision. On general examination he had a spastic paraplegia and sensory loss to the 2nd lumbar segment. He was pyrexial and had consolidation of the lower lobe in the right lung.

The acuities were $6 / 24$ right and 6/5 left. Examination of the left eye was normal. In the right eye the anterior chamber was quiet but there was a marked posterior uveitis. Fundus examination showed a swollen right optic disc and periphlebitis in the temporal retina with associated pigment epithelial atrophy (Fig. 10).

Investigations revealed a haemoglobin of $12 \mathrm{~g} / \mathrm{dl}$, normal leucocyte count, and ESR $56 \mathrm{~mm} / \mathrm{hr}$. Routine biochemical tests were normal. A chest $x$-ray showed patchy infiltration of both lungs with consolidation in the right lower lobe (Fig. 11). The Mantoux test was negative, and serological tests for fungi, viruses, and parasites were negative. Antinuclear factor was negative, and immunoglobulins were normal. Electrophoresis of CSF confirmed the presence of acute inflammatory transudative process but was not diagnostic. HLA tissue type was A1, A2, B8, B12. An open lung biopsy was performed, and histological examination showed granulomata with foci of necrosis in the walls of pulmonary arteries, veins, and bronchioles. There was fragmentation of the elastic lamina in the arterial walls and fibrinoid necrosis, a histiological picture consistent with necrotising sarcoidal granulomatosis. The patient was treated with prednisolone and cyclophosphamide, with resolution of the pulmonary and retinal lesions, but unfortunately little improvement in the paraplegia. One year later the disease was quiescent.

Summary. A 12-year-old boy presented with transverse myelitis, pneumonia, and uveitis. Open lung biopsy confirmed a diagnosis of the necrotising sarcoidal type of Wegener's granulomatosis. His disease has been controlled effectively with immunosuppressive therapy, but he has a severe neurological defect. The signs in the right eye have subsided completely, with some residual disc pallor.

\section{Discussion}

Classical Wegener's granulomatosis has been described as a discrete pathological entity, although there are some similarities with polyarteritis nodosa and allergic angiitis. ${ }^{1-36}$ Wegener's granulomatosis differs from polyarteritis nodosa by the involvement of smaller arteries and veins, the involvement of pulmonary arteries, and the presence of localised necrotising granulomas in the absence of vascular involvement. Typically the clinical picture of initial

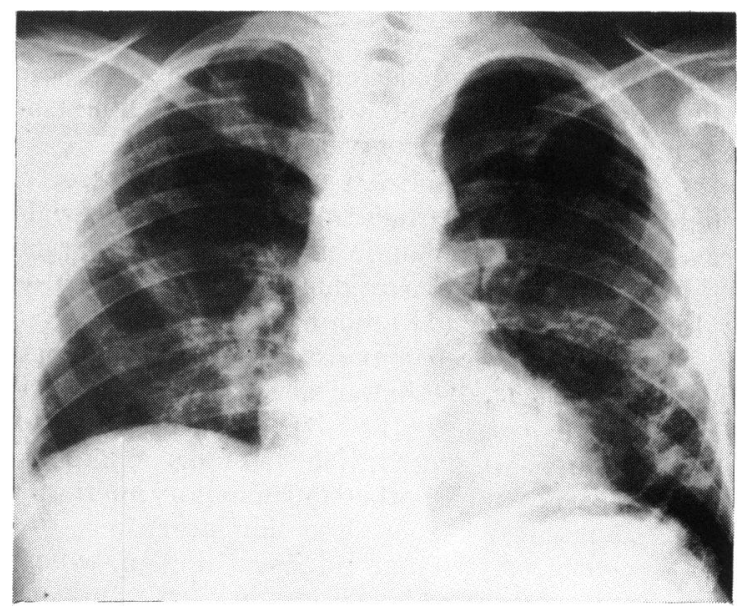

Fig. 11 Case 8 . Chest $\mathrm{x}$-ray showing patchy infiltration of both lung fields with consolidation in the right lower lobe. 
respiratory disease succeeded by renal failure and disseminated vasculitis is characteristic and helps to establish the diagnosis, but individual cases vary, and the differentiation from polyarteritis nodosa or hypersensitivity angiitis can be blurred.

The aetiology of the condition is unknown, but the pathological changes support an immunological basis, and the initial damage to the respiratory tract in Wegener's granulomatosis prior to a more disseminated vasculitis suggests that the antigen or agent responsible gains access to the body in this way. Shillitoe and colleagues ${ }^{10}$ searched for circulating immune complexes unsuccessfully, but they also found that delayed hypersentivity reactions were reduced and postulated that deficient cell mediated immunity might have an aetiological role. Their patients were, however, on immunosuppressive treatment, and more recently it has been suggested that the granulomas contain immune complexes in a type III reaction. "It has been shown that clinical relapses in quiescent disease can be precipitated by infections associated with circulating immune complexes, " but whether this phenomenon is directly related to circulating immune complexes, indirectly to suppression of the reticuloendothelial system, or merely to some other aspect of the generalised tissue response to infection has yet to be shown.

The concept of limited forms of Wegener's granulomatosis has been more commonly recognised since a review of 16 patients with isolated pulmonary disease. ${ }^{5}$ Many of these patients survived for prolonged lengths of time without renal complications and had a much better prognosis and response to treatment than had been previously accepted, and other reports have substantiated this. ${ }^{7}$ Liebow $^{6}$ reviewed pulmonary angiitis and, on pathological appearances, divided the condition into 5 typesclassical Wegener's granulomatosis, limited Wegener's granulomatosis, necrotising sarcoid granulomatosis, lymphomatoid granulomatosis, and bronchocentric granulomatosis. Patients with limited Wegener's granulomatosis had identical pulmonary pathology to those with the classical variety, but had relatively sparse extrapulmonary complications and no renal involvement.. although some patients had disease which disseminated over a number of years. In his report limited Wegener's granulomatosis was found to occur more commonly than classical Wegener's granulomatosis.

Visual damage from Wegener's granulomatosis can be severe. Two patients (numbers 2 and 3 in this series) each lost useful vision from anterior segment problems, another (number 4 ) had an eye enucleated for thrombotic glaucoma, and 2 patients lost vision from optic nerve disease (number 6 and number 7 in both eyes). This represents a total visual loss of 6 out of 16 eyes $(37 \%)$. Severe ocular or optic nerve damage results from long-standing disease and reflects the difficulty in making a tissue diagnosis in these patients and the consequent delay in starting appropriate cytotoxic therapy.

Ocular involvement in Wegener's granulomatosis results from a focal vasculitis or contiguous spread from the upper airways and is reflected in 3 ways: (1) focal vasculitis of the anterior segment and exterior eye; (2) infiltration of the orbit, optic nerves, or lacrimal system; (3) retinal or choroidal disease.

\section{ANTERIOR SEGMENT}

This is the most common site of focal involvement in Wegener's granulomatosis and an awareness of these signs can alert the ophthalmologist to the relevant investigations and diagnosis. Lid and conjunctival inflammation, corneoscleral ulceration, episcleritis, and scleritis are all recognised features. ${ }^{81213}$ Perhaps the commonest finding is of a marginal keratitis or circumlimbal ulceration with scleritis. These signs were first recognised by Straatsma ${ }^{8}$ and Cogan, ${ }^{14}$ who attributed them to an occlusive vasculitis of the anterior ciliary vessels. The appalling prognosis of the disease in this era is underlined by the fact that all 14 of the patients in the series published by Straatsma in 1957 had their diagnosis confirmed at necropsy.

In our experience corneoscleral involvement begins as keratitis, with marginal infiltration identical to that associated with staphlococcal sensitivity. In florid examples (patients $1,2,3$ ) there is also involvement of the tarsal conjunctiva and caruncle by induration, hyperaemia, and small haemorrhages (Fig. 4). On the bulbar surface a localised episcleritis or scleritis is usually present (Fig. 1). The marginal keratitis does not respond well to treatment and persists or relapses over many weeks, eventually coalescing to a ring corneal ulcer (Fig. 3) not unlike a Mooren's ulcer, but with a patchy scleritis. While previous authors have attributed the high incidence of keratitis and scleritis to inflammation and occlusion of the anterior ciliary vessels, with consequent ischaemia, the absence of other early signs of anterior segment ischaemia and the early presence of marginal infiltrates may be an indication of the immunological deficit suffered by these patients, and their failure to overcome a bacterial infection may be an initiating or stimulatory factor for the vasculitis and subsequent tissue necrosis.

ORBITAL INVOLVEMENT

This is one of the better recognised features of Wegener's granulomatosis and is usually attributed to contiguous spread from the adjacent sinuses. It was the predominant feature in 4 of our patients (numbers $5,6,7$, and 8), and all of these patients probably had upper respiratory tract involvement, although this 
was by no means florid, and signs of sinus involvement had to be searched for carefully. Wegener's granulomatosis can affect any of the orbital contents by direct invasion or compression, and the optic nerve damage and lacrimal obstruction seen in patients 6 and 7 is well recognised. ${ }^{15}$ The eyelid involvement in patient 2 is most unusual. Similar signs have been previously reported in a fatal case where the lid disease was found to communicate with the nose at postmortem. ${ }^{16}$ But, while our patient had some evidence of upper respiratory involvement, the lid lesions on both sides appeared to be discrete and free from any deep orbital involvement. Her lid pathology was atypical and showed granuloma formation without vascular necrosis, and a chronic inflammatory reaction was found in the nasal mucosa. Patient 7 tragically lost useful vision in both eyes from intracranial disease. Definitive diagnosis was delayed here as a result of the initial negative neuroradiological investigations and her subsequent disinclination for further procedures. As in so many of these patients, her history of epistaxis was neglected in the initial assessment and sinus involvement was subtle. Surprisingly, in view of her bilateral optic nerve compression, the sphenoidal sinus appeared to be radiologically free of disease (Figs. 9A and B), when a tissue diagnosis was eventually made.

A history of epistaxis, sinusitis, or hearing problems could be obtained from 7 of the 8 patients in this series, though at the time of presentation these symptoms were frequently overshadowed by more dramatic symptoms, and no significance was attended to them. Plain skull $x$-rays help to detect suspicious sinus involvement. This was very useful in helping to establish the diagnosis of Wegener's granulomatosis, as the affected sinus could then be readily inspected and biopsied through an otolaryngological approach under anaesthetic, but the degree of sinus, orbital, or bony involvement is much better demonstrated by axial and coronal CT scanning, which also helps to exclude endocrine exophthalmos or destructive orbital diseases.

\section{RETINAL AND CHOROIDAL INVOLVEMENT}

This appears to be uncommon in Wegener's granulomatosis, and only 1 patient in our series had evidence of retinal vasculitis. This boy was interesting in that the pulmonary pathology showed the necrotising sarcoidal type of pathology, and one might speculate that the pathological similarity to sarcoidosis was reflected in the clinical presentation of pulmonary mottling, a transverse myelitis, and retinal vasculitis. This patient has many similarities to the one reported by Coutu et al. ${ }^{17}$ with limited Wegener's granulomatosis. We have also seen another patient (not included in this series) who had generalised Wegener's granu- lomatosis and subsequently developed choroidal detachments. He was treated with plasmaphoresis with a dramatic response in the ocular pathology, which resolved to leave a fundus picture not unlike that of case 3 reported by Haynes et al. ${ }^{12}$

Other authors have reported central retinal artery occlusions in Wegener's granulomatosis, and, while we have not seen this complication, patient 4 initially presented with a central retinal vein occlusion (without other signs of orbital involvement) leading to enucleation for thrombotic glaucoma. Presumably these large vessels can be directly involved by focal vasculitis. The diagnosis in this patient was suggested by subsequent marginal keratitis and uveitis in his remaining eye and a systemic malaise with high ESR. He was the only patient in this series to have definite renal involvement but has made an excellent response to steroid therapy alone.

We thank Dr D. G. James for permission to include patient 3 and the Professorial Unit, Moorfields Eye Hospital, for permission to include patient 2. Professor Alec Garner, from the Institute of Ophthalmology, kindly provided the ocular pathology reports on patients 2 . 3 , and 4 . The pathology of case 6 has been previously reported ${ }^{18}$ and the paediatric aspects of case 8 have also been published. ${ }^{19}$

We are grateful to Miss Josephine Lace for typing the manuscript and Mr Rolf Sennhenn for the preparation of the illustrations.

\section{References}

1 Wegener F. Uber generalisierte septische Gefrasserkrankungen. Verh Pathol Dtsch Ges 1937; 29: 202-10.

2 Wegener $F$. Uber eine eigenartige rhinogene Granulomatose mit besonderer Beteiligung des Arteriensystems und der Nieren. Beitr Pathol 1939; 102: 36-68.

3 Godman AC, Churg, J. Wegener's granulomatosis. Pathology and review of the literature. Arch Pathol 1956; 58: 533-53.

4 Walton EW. Giant cell granuloma of the respiratory tract (Wegener's granulomatosis). Br Med J 1958; ii: 265-70.

5 Carrington CB, Liebow AA. Limited forms of angiitis and granulomatosis of Wegener's type. Am J Med 1966; 41: 497-527.

6 Liebow AA. Pulmonary angiitis and granulomatosis (Burns Amberson lecture). Am Rev Resp Dis 1973; 108: 1-18.

7 Cassan SM, Coles DT, Harrison EG. The concept of, limited forms of Wegener's granulomatosis. Am J Med 1970; 49: 366-79.

8 Straatsma BR. Ocular manifestations of Wegener's granulomatosis. Am J Ophthalmol 1957; 44: 789-99.

9 Fauci AS, Wolff SM. Wegener's granulomatosis. Studies in 18 patients and a review of the literature. Medicine 1973; 52: 535-61.

10 Shillitoe EJ, Lehner T, Lessof M, Harrison DFN. Immunological features of Wegener's granulomatosis. Lancet 1974; i: 281-4.

11 Pinching AJ, Rees AJ, Pussell BA, Lockwood CM, Mitchison RS, Peters DK. Relapses in Wegener's granulomatosis: the role of infection. Br Med J 1980; 281: 836-8.

12 Haynes BF. Fishman ML, Fauci AS, Wolff SM. Ocular manifestations of Wegener's granulomatosis-15 years experience and a review of the literature. Am J Med 1977; 63: 131-41.

13 Ferry AP. Leopold IH. Marginal (ring) corneal ulcer as a presenting manifestation of Wegener's granuloma. A clinical pathological study. Trans Am Acad Ophthalmol Otolaryngol 1970; 74: 1276-82.

14 Cogan DG. Corneoscleral lesions in periarteritis nodosa and Wegener's granulomatosis. Trans Am Ophthalmol Soc 1955; 53: 321-44. 
15 Cassan SM. Divertie MB. Hollenhorst RW. Harrison EG. Pseudotumour of the orbit and limited Wegener's granulomatosis. Ann Intern Med 1970; 72: 687-93.

16 Verrey von F, Landolt E. Augensymptone der Wegenerschen Granulomatose. Ophthalmologica 1967; 153: 309-20.

17 Coutu RE, Klein M, Lessell S, Friedman E, Snider GL. Limited form of Wegener's granulomatosis: eve involvement as a major sign. JAMA 1975; 233: 868-71.

18 Pambakian $\mathrm{H}$. Tighe JR. Breast involvement in Wegener's granulomatosis. J Clin Pathol 1971: 24: 343-7.

19 Beach RC. Corrin B. Scopes JW. Graham E. Necrotizing sarcoid granulomatosis with neurological lesions in a child. $J$ Pediatr in press. 